\title{
SIGNOS VISUAIS, VERBAIS E NÃO-VERBAIS DO DISCURSO QUADRINÍSTICO
}

\author{
VISUAL SIGNS, VERBAL AND NON-VERBAL SIGNS OF THE LANGUAGE OF COMICS
}

\author{
Lucas Piter Alves Costa \\ Universidade Federal de Minas Gerais
}

RESUMO: Os quadrinhos constituem um sistema semiótico que pode conjugar ao mesmo tempo signos verbais, não-verbais e visuais, sendo muito mais que a simples junção de "palavras" e "imagens". Defendemos que o sentido de um discurso se apoia em três pontos que devem ser analisados: o sistema, os sujeitos, a situação histórica. Neste trabalho, pretendemos mostrar pontos de funcionamento do sistema e elucidar a relação dos signos que compõem a linguagem quadrinística e, de maneira geral, seus possíveis efeitos de sentido na tradução intersemiótica d'O Alienista, de Fábio Moon e Gabriel Bá. Dos autores que nos servem de base, citamos Barthes (1964, 1990), Costa (2013), Joly (2007) e McCloud (1995, 2008).

PALAVRAS-CHAVE: signos visuais; tradução intersemiótica; linguagem quadrinística.

ABSTRACT: The comics constitute a semiotic system that combines at the same time verbal signs, non-verbal signs and visuals signs, being much more than a mere combination of "word" and "images ". We defend that the production of meaning is constructed on three points that must be analyzed: the system, the subjects involved and the historical situation. In this work, we intend to elucidate the relationship of these signs that constitute the language of comics and, in general way, the possible effects of meaning in intersemiotic translation of $O$ Alienista, by Fábio Moon and Gabriel Bá. Among the authors who served as a basis, we quote Barthes (1964, 1990), Costa (2013), Joly (2007) and McCloud (1995, 2008).

KEYWORDS: visual signs; translation intersemiotic, language of comics.

\section{Apresentação}

A prática de leitura de uma história em quadrinhos é muito mais que a mera decodificação de uma mensagem verbal ancorada a uma mensagem visual, por vezes vista apenas como ilustração. Ler quadrinhos é "ler sua linguagem. Dominá-la, mesmo que em seus conceitos mais básicos, é condição para a plena compreensão da história e para [...] pesquisas científicas sobre o assunto." (RAMOS, 2010, p. 30). Ler uma história em quadrinhos exige do leitor a compreensão do funcionamento conjugado de diversos signos (verbais, não-verbais e visuais) que compõem a semiótica ${ }^{1}$ dos quadrinhos.

Assim, neste trabalho, para uma possível proposta de análise do discurso,

\footnotetext{
${ }^{1}$ Usamos o termo semiótica em sentido lato: um sistema de signos que funciona como uma linguagem capaz de instituir algum sentido.
} 


\section{Revista do SELL \\ v. $4, n^{\circ} .1$ \\ ISSN: $1983-3873$}

pretendemos expor alguns aspectos da linguagem dos quadrinhos. Para esse fim, utilizaremos como exemplo a tradução intersemiótica d'O Alienista, de autoria de Fábio Moon e Gabriel Bá. O Alienista em quadrinhos é uma adaptação homônima do conto de Machado de Assis. Publicada pela Editora Agir, a adaptação abre a série Grandes Clássicos em Graphic Novel.

\section{Os signos d'O Alienista}

\subsection{Signos visuais}

Joly $(1994,2007)$ assinala que a mensagem visual per se é composta por signos icônicos e signos plásticos. Por signos icônicos, ou figurativos, Joly (2007) entende como sendo as imagens usadas para se assemelhar ou representar objetos do mundo, ou seja, as figuras. Os signos icônicos "dão uma impressão de semelhança com a realidade jogando com a analogia perceptiva e com os códigos de representação herdados da tradição de representação ocidental." (JOLY, 2007, p. 75). Em outras palavras, esses signos evocam conotações socioculturalmente determinadas, por isso dependem muito do contexto empregado.

Por signos plásticos, Joly (2007) considera as cores, as formas, a composição e a textura. Ela inclui nesses recursos o quadro (moldura) e o enquadramento (focalização). O enquadramento (o olhar para o objeto) não deve ser confundido com o quadro (o contorno do olhar). O quadro "é o limite da representação visual, o enquadramento corresponde ao tamanho da imagem, suposto resultado da distância entre o objeto [e o olhar do narrador/narratário]." (JOLY, 2007, p. 94).

Em se tratando de história em quadrinhos, entendemos que os elementos plásticos são extradiegéticos, estão fora da história. São elementos que direcionam a leitura, não a história. São recursos empregados na instância enunciativa ou ergo-textual (COSTA, 2013; PEYTARD, 2007 [1983]). Em todo caso, o uso de tais recursos interfere diretamente na forma do gênero.

Em suma, os signos plásticos usados como recurso pelo quadrinista singularizam o que os signos icônicos representam. Enquanto o signo icônico busca o conceito, o signo plástico conceitua essa busca, tornando a representação do objeto mais ou menos valorizada, objetiva, subjetiva, técnica, ou artística, de modo que atenda às necessidades 


\section{Revista do SELL}

v. $4, n^{\circ} .1$

ISSN: $1983-3873$

discursivas, situacionais e formais do gênero. ${ }^{2}$

Um signo plástico tende a ter significados técnicos, mas pode evocar conotações também, neste caso, em favor do signo icônico e da situação de comunicação. A imagem seguinte nos serve de exemplo para extrair uma série desses signos. Vejamos como podem ser agrupados e interpretados, levando-se em conta o contexto da imagem:

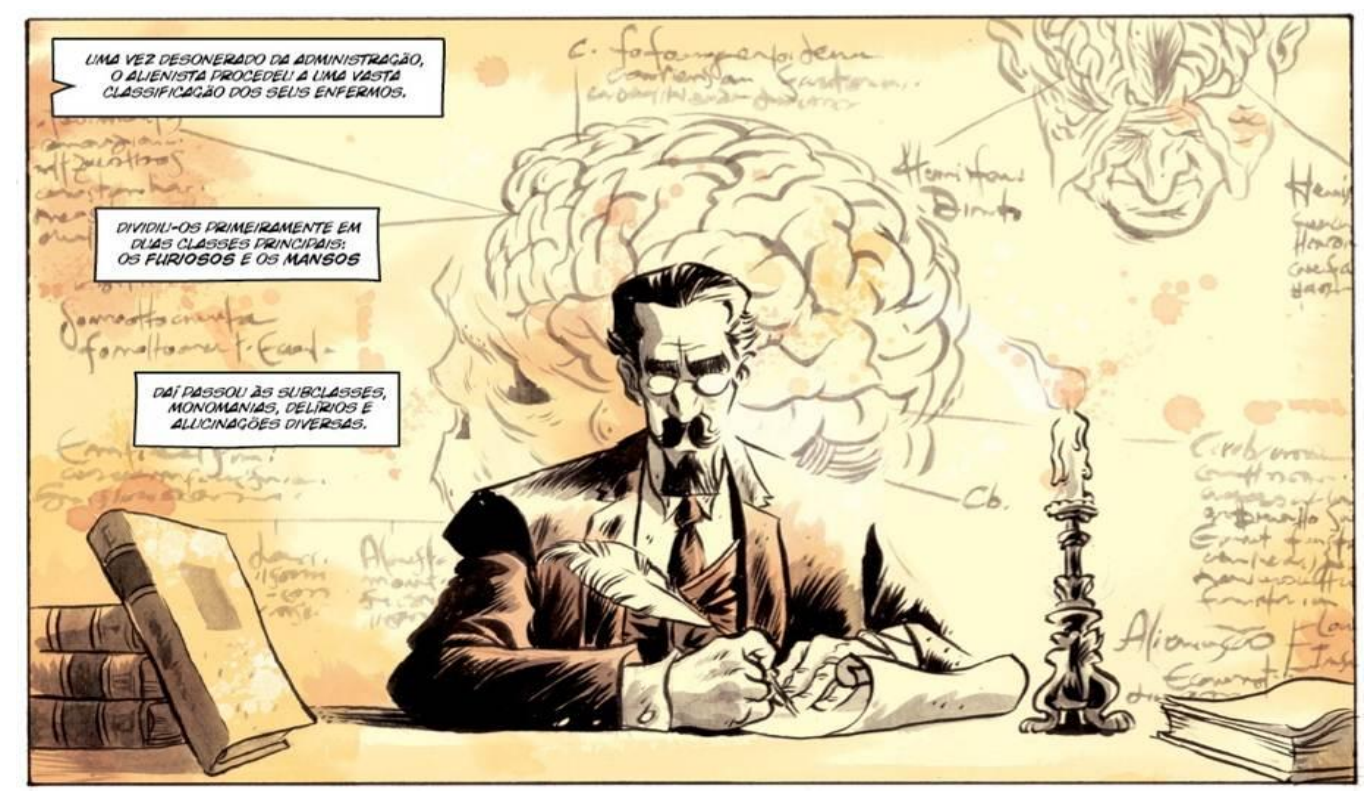

Figura 1: O Alienista. Signos. (p. 15).

Tabela 1: Signos icônicos n'O Alienista

\begin{tabular}{|c|c|c|}
\hline \multicolumn{2}{|c|}{ Signos icônicos } \\
\hline Significantes & Significados imediatos & Conotações atribuíveis \\
\hline Homem maduro & O alienista, Simão Bacamarte & $\begin{array}{c}\text { Cientista, sábio, erudito, louco, médico, doutor, } \\
\text { autoridade }\end{array}$ \\
\hline Terno & Vestimenta & Vestimenta de prestígio, status, poder \\
\hline Óculos & Leitura, enxergar & Erudição, sabedoria, ciência \\
\hline Pena & Escrita, trabalho & Conhecimento, poder da palavra \\
\hline Vela & Luz & Noite, trabalho árduo, leitura \\
\hline Livros & Biblioteca & $\begin{array}{c}\text { Conhecimento, sabedoria, status, poder, trabalho, } \\
\text { ciência }\end{array}$ \\
\hline Manuscrito & Escrita, trabalho, anotações & Conhecimento, poder da palavra, trabalho, ciência \\
\hline $\begin{array}{c}\text { Cérebro/ } \\
\text { anotações ao } \\
\text { fundo }\end{array}$ & Fundo & $\begin{array}{c}\text { Pensamentos, conteúdo das anotações, } \\
\text { conhecimento }\end{array}$ \\
\hline
\end{tabular}

${ }^{2}$ Cf. Charaudeau (2004) para compreender o funcionamento dessas necessidades - ou restrições - do gênero. Ainda, em Joly (2007) há um exemplo de como os signos plásticos e icônicos são empregados em uma publicidade, atendendo às restrições discursivas, situacionais e formais do gênero. 


\section{Revista do SELL}

v. $4, n^{\circ} .1$

ISSN: $1983-3873$

Tabela 2: Signos plásticos n'O Alienista

\begin{tabular}{|c|c|c|}
\hline \multicolumn{2}{c|}{ Signos plásticos } \\
\hline Significantes & Significados imediatos & Conotações atribuíveis \\
\hline Quadro & Grande, contornado & Amplitude, conteúdo em destaque \\
\hline Enquadramento & Médio & Equilíbrio, intimidade \\
\hline Ângulo & Frontal & Equilíbrio, simetria, franqueza \\
\hline Cores & $\begin{array}{c}\text { Aquareladas, sépia, alto } \\
\text { contraste }\end{array}$ & $\begin{array}{c}\text { Antiguidade, tempo passado, envelhecido, } \\
\text { seriedade }\end{array}$ \\
\hline Traços & Pincéis & Clássico, antigo, subjetividade \\
\hline Recordatários & Falas do narrador & Remetem a pedaços de papel, manuscritos \\
\hline
\end{tabular}

O enquadramento tem dupla dimensão no processo narrativo: ele é um procedimento que direciona/condiciona a leitura da história e também é responsável por um tipo de focalização que faz surgir um tipo de narrador. Após definir que momentos serão representados na história, o ato de enquadrar que se sucede daí consiste em escolher "a distância e o ângulo corretos para ver esses momentos e onde cortá-los." (McCLOUD, 2008, p. 10). Logo, o enquadramento é resultado da relação estabelecida entre o olhar do narrador (que passa a ser o olhar do narratário também) e o objeto da diegese.

De acordo com Ramos (2010), parece haver consenso entre os diferentes teóricos dos quadrinhos quanto aos tipos de enquadramentos. A distância é categorizada em planos. O ângulo é o ponto de visão do narrador/narratário dentro de um plano. Os planos são: (1) plano em perspectiva; (2) plano de detalhe, pormenor ou close up (plano fechado); (3) primeiro plano; (4) plano médio ou aproximado; (5) plano americano; (6) plano total ou de conjunto; (7) plano geral ou panorâmico. Os ângulos são: (1) ângulo de visão médio; (2) de visão superior ou plongé; (3) de visão inferior ou contra-plongé.

O enquadramento pode aproximar ou distanciar, ocultar ou revelar, e hierarquizar essa relação de saber entre o olhar e o olhado (dependendo do enquadramento, o narrador/narratário pode saber mais ou menos que os personagens). Em outras palavras, o enquadramento situa e/ou posiciona o leitor. Por meio dele, estabelece-se uma relação interpessoal (embora assimétrica) entre os sujeitos do ato de linguagem quadrinístico. $\mathrm{Na}$ narrativa em quadrinhos d'O Alienista, é como se, à moda machadiana, o narrador quadrinístico dissesse: "Veja isto, caro leitor", ao invés de "Vem comigo, caro leitor".

Diferentes enquadramentos podem criar diferentes efeitos de sentidos, sendo impossível elencar todos esses efeitos aqui. O importante é saber que geralmente uma história faz uso de vários enquadramentos, e que, tomados isoladamente, podem ter 


\section{Revista do SELL \\ v. $4, n^{\circ} .1$}

ISSN: $1983-3873$

sentidos distintos daqueles que teriam se tomados no conjunto da história. É por essa razão que a tentativa de extrair algum sentido desses enquadramentos nas histórias em quadrinhos não deve se dar ao molde das análises de discursos publicitários, sobretudo os impressos. Embora a gramática do enquadramento seja a mesma, sua semântica é bem outra.

Alguns efeitos de sentido desses enquadramentos podem ser recorrentes, como são nos casos de planos fechados ou close up, que visam geralmente efeitos patêmicos quando focam a expressão de um personagem como suporte de alguma emoção crucial para a narrativa, como se vê no segundo quadro (Q2) da sequência abaixo ${ }^{3}$, que anuncia a mudança de paradigma do alienista no trato da loucura.

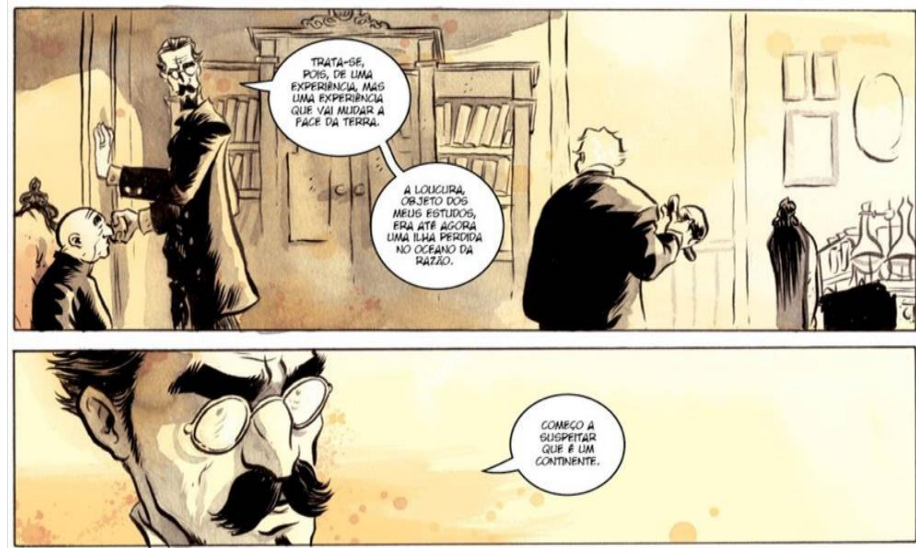

Figura 2: Planos médio e fechado.

Outro exemplo está nos planos panorâmicos a seguir. Com ângulo médio (Q1) e superior (Q2), esses planos distanciam o leitor/narratário, possibilitam transmitir o clima do cenário e situam o personagem.

\footnotetext{
${ }^{3}$ A nomenclatura que estabelecemos para fins didáticos sobre a designação dos quadros em um recorte é a seguinte: $Q$ para quadro, seguido de um número que designa sua posição no recorte analisado, não na página da revista. Ex.: Q2 para designar o segundo quadro de uma sequência analisada de dois ou mais quadros. Q2-3 para designar, por exemplo, uma sequência do segundo quadro ao terceiro, numa série recortada para análise de três ou mais quadros. A numeração dos quadros em um recorte é diferente da numeração da página original. Essa nomenclatura será proeminente no capítulo três, mais especificamente na seção sobre as transições de quadro a quadro.
} 


\section{Revista do SELL}

v. $4, n^{\circ} .1$

ISSN: $1983-3873$
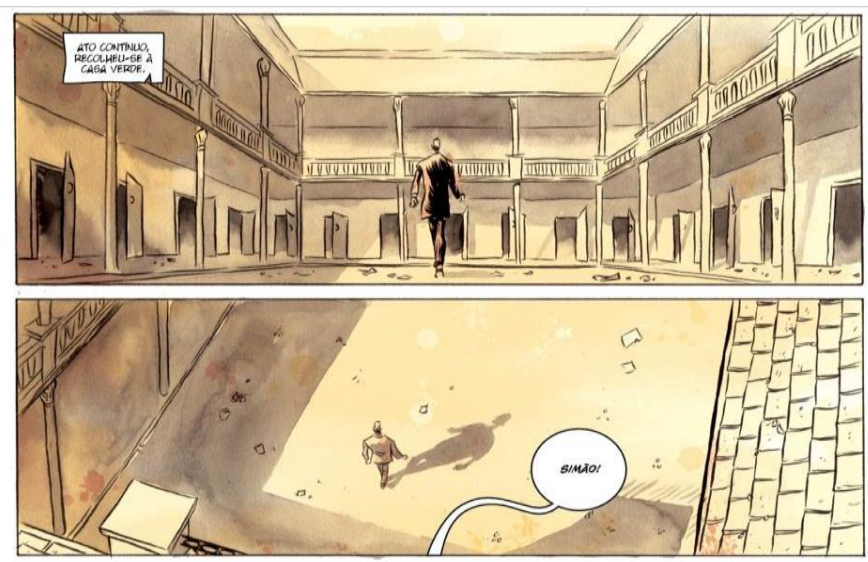

Figura 3: Planos panorâmicos com ângulos médio e superior.

Por sua vez, as cores, como elementos plásticos, são interpretadas de acordo com as condições sócio-históricas de seus usos. Elas assumem conotações situadas e contextuais, e ainda podem assumir significações pessoais, de acordo com os parceiros da troca linguageira. De fato, a cor e a iluminação "têm um efeito psicofisiológico sobre o espectador porque, 'percebidas oticamente e vividas psiquicamente', colocam o espectador em um estado que 'se assemelha' ao de sua experiência primordial e fundadora das cores e da luz." (JOLY, 2007, p. 100). Em suma, os efeitos de sentido possíveis das cores fazem parte do repertório de experiências dos sujeitos, que são evocadas na interpretação do objeto.

As cores e traços n'O Alienista criam um efeito de antiguidade, de tempo passado e de envelhecimento à medida que são associados aos signos icônicos que reforçam essas conotações (vestimentas, cortes de cabelo, carruagem, arquitetura, uso de guarda-sóis e de chapéus...). As cores, em tons de sépia, são conjugadas com traços de pincéis e aguada, causando um efeito de aquarela. ${ }^{4}$

\footnotetext{
${ }^{4}$ Fábio Moon utiliza pincel e aguada (tinta nanquim diluída em água) em seus desenhos. Gabriel Bá utiliza caneta nanquim. N'O Alienista, a diferença no resultado dos desenhos pode ser conferida comparando a capa (feita por Bá) e o miolo (desenhado por Moon). O esboço é feito a lápis por ambos. O processo de produção dos autores pode ser acompanhado no blog 10 Pãezinhos, onde encontramos declarações como esta: "Adoro fazer arte final. Adoro desenhar com o pincel, definindo volumes de traço, preenchendo espaços vazios com preto, eternizando em erros e acertos um desenho." (MOON, 2011, web).
} 


\section{Revista do SELL}

v. $4, n^{\circ} .1$

ISSN: $1983-3873$

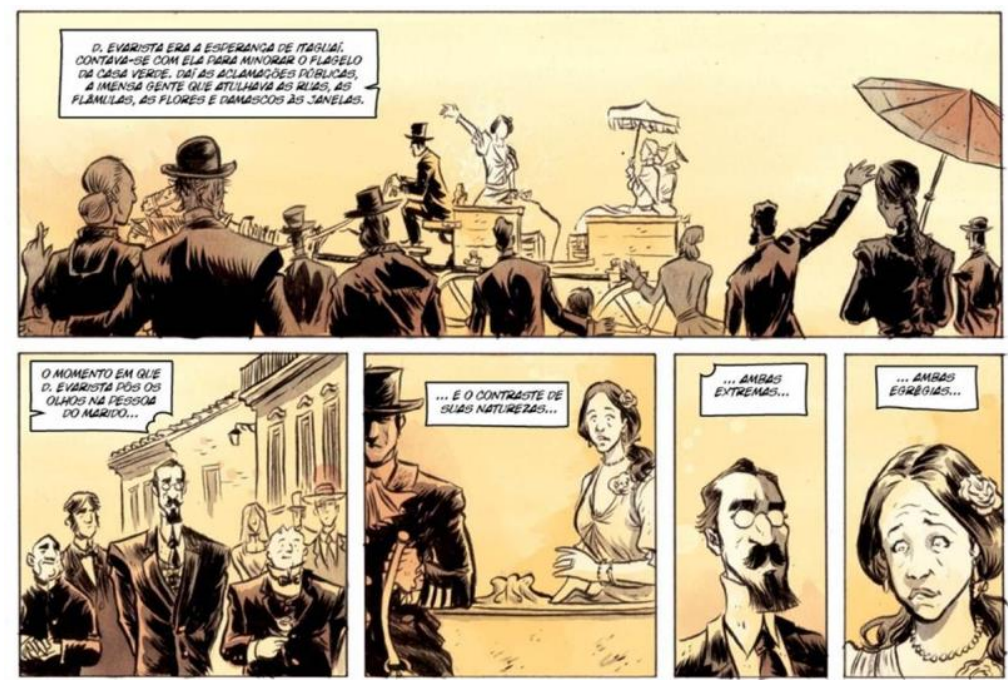

Figura 4: O Alienista. Cores, traços e signos icônicos. (p. 31).

É verdade que a interpretação desses elementos pode tomar tantos rumos quantos forem os sujeitos-interpretantes. Por seu caráter essencialmente subjetivo, o uso das cores e de traços específicos é comumente atrelado ao estilo do artista. Embora seja um ponto de difícil interpretação (se quisermos uma resposta objetiva para um objeto subjetivo), é inegável que o estilo de cada quadrinho comunica algum efeito de sentido.

Cedo ou tarde, o assunto (ou a questão) do estilo da arte vem à tona para o processo da narrativa gráfica. A proporção de sua importância com relação a outros elementos é discutível, mas trata-se de um ingrediente inescapável. A realidade é que o estilo de arte conta uma história. [Os quadrinhos são] um meio gráfico e o leitor absorve o tom e outras abstrações através da arte. O estilo de arte não só conecta o leitor com o artista, mas também prepara a ambientação e tem valor de linguagem. (EISNER, 2005, p. 159).

Por meio de traços e cores, o desenhista pode expressar o invisível, como a atmosfera de uma cidade ou o estado emocional de um personagem. Esses efeitos visuais não transparecem na história, mas sim na organização do discurso. São efeitos geralmente direcionados ao leitor-possível, não ao narratário.

O plano fechado abaixo foca a expressão do barbeiro Porfírio na cena em que o alienista não atendeu às exigências dos revoltosos de fechar a Casa Verde. Toda a multidão ficara atônita com a atitude serena do alienista diante daqueles que pediam a sua cabeça. Foi o momento em que o barbeiro sentiu com furor a ambição de governo e provocou toda a multidão a invadir a Casa Verde. 


\section{Revista do SELL}

v. $4, n^{\circ} .1$

ISSN: $1983-3873$

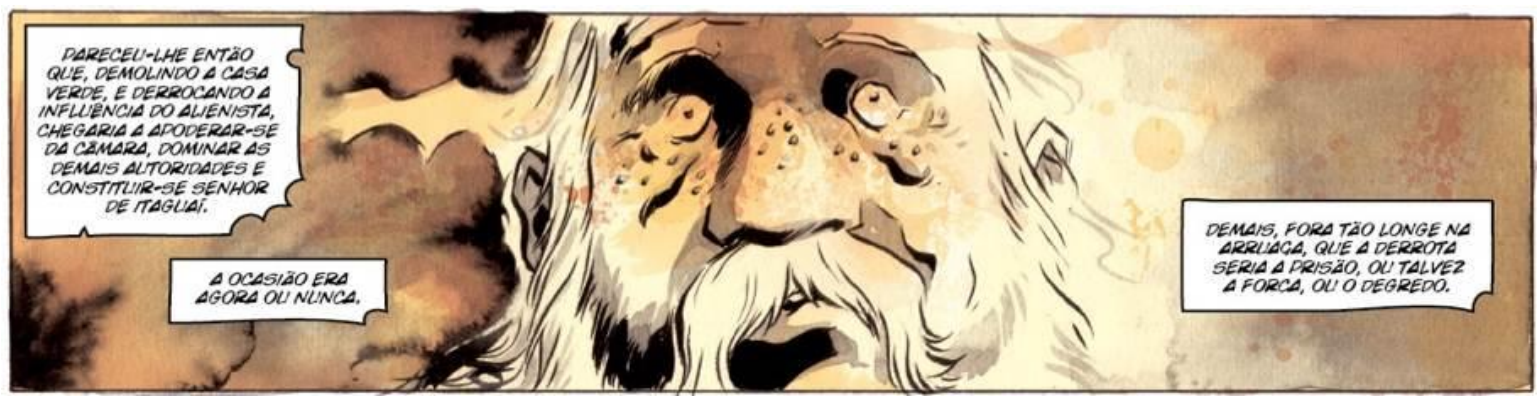

Figura 5: O Alienista. Loucura do barbeiro. (p. 43).

Como interpretar a imagem acima? Bom, para não cair em subjetivismo, o analista deve partir daquilo que for mais evidente primeiro. Alguns fatores auxiliam na interpretação, ou melhor, direcionam a mesma: (1) A cena corresponde ao clímax da história, então podemos pressupor que a tensão era maior (fator contextual). (2) O uso de plano fechado, ou close up, se dá geralmente para isolar um aspecto importante, o único que deve ser visto então (fator técnico). Podemos entender que seja a emoção por trás da expressão do barbeiro. Logo, há uma emoção que consiste no âmago da mensagem. (3) O estrato verbal traz informações explícitas sobre as intenções do barbeiro - não sobre suas emoções (fator linguístico). (4) As pupilas extremamente retraídas são signos icônicos que, nos quadrinhos, representam algum estado emocional arrebatador (fator genérico). Com essas informações, é possível direcionar a interpretação dos traços atípicos e da nuança de tons presentes na imagem para algum efeito de sentido visado na narrativa. Porfírio foi tomado por uma gama de emoções tão fortes que culminaram no enfrentamento da força armada dos Dragões, logo em seguida. A sentença do alienista para essa atitude não foi outra: loucura.

\subsection{Signos verbais}

O senso comum pode representar a ideia de que os quadrinhos são a mera junção de imagens e palavras. Os elementos que abordamos até então mostram que não é só isso. É possível haver quadrinhos sem palavras, mas não sem imagens. Isso nos leva a crer que as palavras não são um recurso obrigatório nos quadrinhos, embora tenham desempenhado um papel importante no avanço dessa mídia: por meio dos balões de fala, recordatários e onomatopeias, as palavras ampliaram as possibilidades de recursos gráficos das histórias. Quando "palavras e imagens atuam interdependentemente, elas podem criar novas ideias e sensações muito além da soma das partes.”. (McCLOUD, 2008, p. 128). As palavras, então, são encenadas de modo a servirem aos propósitos da narrativa em quadrinhos. A organização do discurso quadrinístico tende a buscar o equilíbrio entre os signos plásticos, 


\section{Revista do SELL \\ v. $4, n^{\circ} .1$ \\ ISSN: $1983-3873$}

icônicos e linguísticos, formando uma linguagem de caráter multimodal, com estratos sígnicos indivisíveis. O conceito de multimodalidade que entendemos se relaciona à multiplicidade de modalidades de linguagem envolvidas em qualquer gênero discursivo oral ou escrito.

Textos multimodais são aqueles nos quais mais de uma modalidade converge em uma situação para produzir significado. $O$ canal linguístico em textos multimodais pode ser falado ou escrito ou qualquer combinação desses e de outros modos semióticos implantados, pode ser físico ou visual ou qualquer combinação desses. ${ }^{5}$ (BOWCHER, 2007, p. 630, tradução nossa).

O relacionamento entre palavras e imagens pode criar diversos efeitos de sentido, de modo que essa variação pode ser categorizada de acordo com algumas recorrências. Das sete categorias propostas por McCloud (1995, 2008), vemos que três podem ser agrupadas nas relações de ancoragem e quatro nas de revezamento, categorias propostas por Barthes (1964, 1990) para a conjugação de palavras e imagens.

A fixação [ancoragem] é a função mais frequente da mensagem linguística: é comumente encontrada na fotografia jornalística e na publicidade. A função de relais [revezamento] é mais rara (pelo menos no que concerne à imagem fixa); vamos encontrá-la sobretudo nas charges e nas histórias em quadrinhos. (BARTHES, 1990, p. 33).

De acordo com Barthes (1964, 1990), a ancoragem consiste em descrever uma relação entre palavras e imagens, na qual as palavras indicam o nível correto de leitura da imagem. A imagem estaria ancorada à mensagem linguística.

Para Barthes, na relação de ancoragem, a mensagem linguística orienta não apenas a identificação, mas a interpretação, impedindo os sentidos conotados [da imagem] de proliferarem em direção a regiões demasiadamente individuais. Ou seja, a mensagem linguística limitaria o poder projetivo da imagem. (MELO, 2003, p. 17).

Tal como Melo (2003), acreditamos que a função de ancoragem pode se dar em dois sentidos: tanto a mensagem linguística pode ancorar a mensagem visual, quanto a mensagem visual pode ancorar a mensagem linguística. Dessa forma, a cadeia flutuante de sentidos de uma imagem pode ser direcionada pelo estrato verbal atrelado a ela; ou a polissemia de uma mensagem verbal pode ser anulada ao ser contextualizada pela imagem

\footnotetext{
5 Texto original: Multimodal texts are those in which more than one modality converges in a situation to produce meaning. The linguistics channel in multimodal texts may be spoked or written or any combination of these and the other semiotic modes deployed may be physical or visual or any combination of these.
} 


\section{Revista do SELL \\ v. $4, n^{\circ} .1$ \\ ISSN: $1983-3873$}

a que se refere.

Já a relação de revezamento, "é uma forma de complementaridade entre a imagem e as palavras, a que consiste em dizer o que a imagem dificilmente pode mostrar." (JOLY, 2007, p. 119). Na relação de revezamento, a ausência de um dos estratos pode interferir na interpretação, uma vez que a relação entre eles é de complementaridade. Acreditamos que, nos quadrinhos, essa relação ocorre também da imagem para com as palavras: o estrato visual (composto por signos icônicos e plásticos) pode "comunicar" um (efeito de) sentido que as palavras sozinhas não poderiam sem correr o risco de tornar a obra de quadrinhos em uma "prosa ilustrada". Haja vista sobre os efeitos que o enquadramento de um personagem ou de uma paisagem pode ter em uma narrativa, efeitos esses de difícil descrição pelo estrato verbal numa mídia em que se espera a concisão. Vejamos, portanto, as categorias propostas por McCloud $(1995,2008)$ e sua síntese com as categorias de ancoragem e revezamento, e como elas se dão n'O Alienista.

\section{a) Específica da palavra}

As combinações específicas da palavra ocorrem quando toda a informação necessária para o leitor é transmita pelo estrato verbal, "enquanto as imagens ilustram aspectos da cena que está sendo descrita." (McCLOUD, 2008, p. 130). Dessa forma, a imagem está ancorada ao texto: sua interpretação não pode ir além do que o estrato verbal diz.

Combinações desse tipo são muito úteis em narrativas cujo conteúdo da história é extenso, e o quadrinista dispõe de pouco espaço para escrevê-la, como é o caso d'O Alienista ou de outras traduções intersemióticas. Combinações específicas da palavra reduzem "grandes volumes de informação e tempo a umas poucas e breves palavras." (McCLOUD, 2008, p. 130).

No fragmento abaixo, incontáveis eventos foram sintetizados pelas palavras, sendo que as imagens narram algum aspecto desses eventos. 

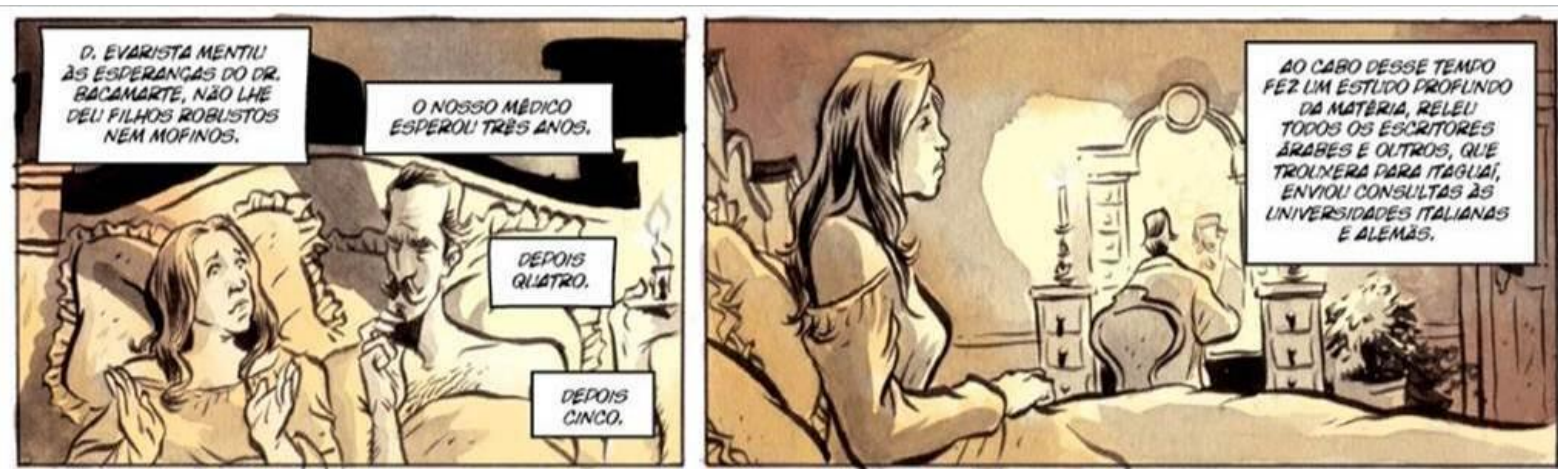

Figura 6: 0 Alienista. Específica da palavra. (p. 17).

Outra utilidade desse tipo de combinação é que, ao deixar às palavras a responsabilidade de narrar, ela permite que o uso do estrato visual seja mais flexível. Com toda informação sendo expressa pelo estrato verbal, a arte do quadrinista pode se expandir, seguindo inúmeras direções diferentes, mas sempre mantendo um elo firme com a parte verbal. A imaginação do leitor também pode seguir direções diversas, pois as imagens fazem alusão a algum aspecto da cena narrada, ficando o restante para o leitor deduzir, inferir ou imaginar.

\section{b) Específica da imagem}

Este tipo de combinação é similar à anterior, mas dessa vez são as imagens que proporcionam todas as informações necessárias, "enquanto as palavras acentuam aspectos da cena que está sendo exibida." (McCLOUD, 2008, p. 130). A palavra, então, está ancorada à imagem: sua interpretação se restringe pelo que o estrato visual comunica, não podendo ir muito além desse.

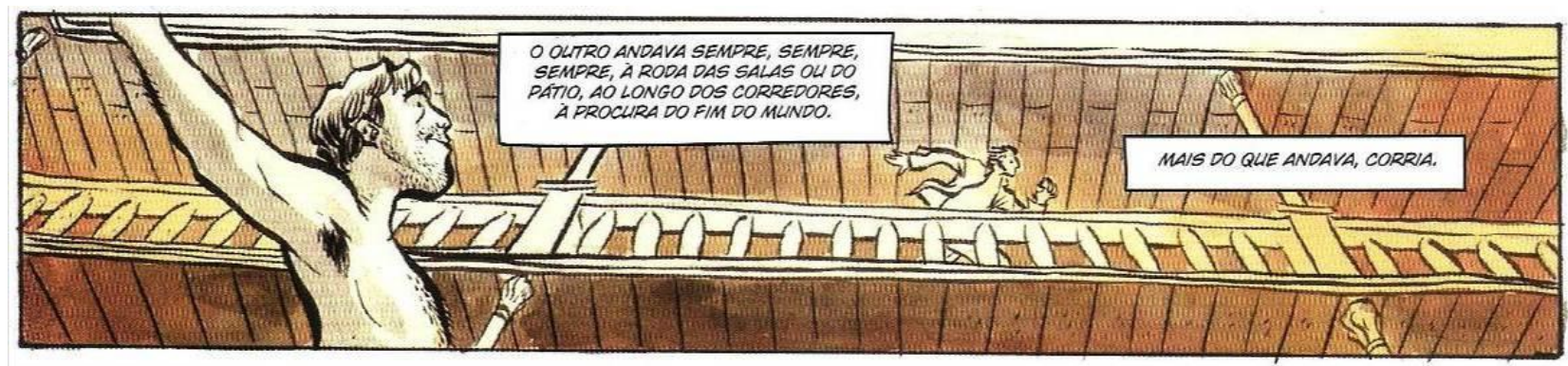

Figura 7: O Alienista. Específica da imagem. (p. 13).

O fragmento acima consiste na cena que mostra alguns loucos da Casa Verde. O estrato verbal não descreve informação que possa mudar radicalmente a interpretação do quadro. Não é preciso dizer que a interpretação deve ser contextualizada, o que nos obriga a 


\section{Revista do SELL}

v. $4, n^{\circ} .1$

ISSN: $1983-3873$

considerar outros trechos da cena.

\section{c) Específica da dupla}

Neste tipo de combinação, por transmitirem aproximadamente a mesma mensagem, palavra e imagem estão ancoradas uma na outra, de modo que cada estrato direciona simultaneamente a interpretação do outro. O resultado é uma combinação redundante. "Felizmente, os modernos quadrinistas evitam a redundância a maior parte do tempo." (McCLOUD, 2008, p. 135). Neste tipo de combinação, não ocorre distinção entre o tempo e espaço comunicado nos estratos: eles coincidem.

Por sua natureza, o texto machadiano mistura narração de eventos com intervenção do narrador, ou, às vezes, interrompe a narração para explicar um fato, ou, ainda, salta de um evento a outro sem explicação, criando uma narrativa labiríntica. Como muito do texto original foi mantido em inúmeras sequências da história em quadrinhos, e devido à quantidade de informação que cada trecho do texto machadiano veicula, não foi possível encontrar nenhuma parte da graphic novel que apresentasse a redundância necessária para caracterizar uma combinação específica da dupla.

\section{d) Interseccional}

$\mathrm{Na}$ comunicação por combinações interseccionais ou aditivas, palavras e imagens cobrem algum terreno comum da mensagem, tal qual ocorre nas combinações anteriores, mas ambas - palavras e imagens - acrescentam ainda conteúdos significativos ausentes em um e outro estrato da mensagem quadrinística. Em outros termos, o estrato verbal e o visual se complementam, revezando o peso e a responsabilidade de criar os efeitos de sentido na narrativa.

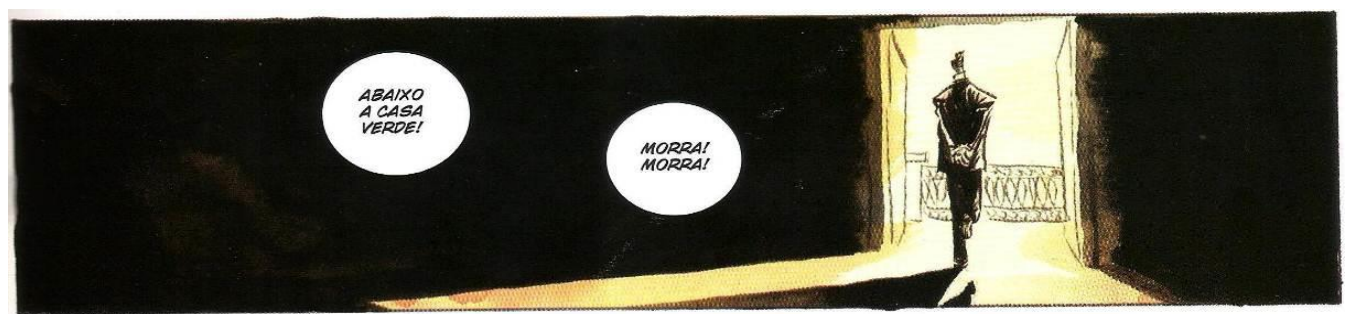

Figura 8: O Alienista. Interseccional. (p. 41).

Outra característica dessa combinação é que o estrato verbal e o visual comunicam o mesmo tempo e espaço: a intersecção entre eles é algum elemento localizável no texto, não 


\section{Revista do SELL}

v. $4, n^{\circ} .1$

ISSN: $1983-3873$

havendo nenhuma anacronia.

No quadro que selecionamos, estrato verbal e visual abrangem a Casa Verde e a pessoa do alienista. O primeiro balão remete ao local onde Simão está; o segundo balão remete à sua pessoa, pois o povo de Itaguaí deseja que o alienista morra. O quadro mantém uma coesão, de modo que um ou outro elemento de cada estrato se retomam mutuamente (de forma não linear, já que não há uma ordem pré-estabelecida de leitura entre imagem e palavra).

Esses estratos separados não teriam, evidentemente, o mesmo sentido que eles têm conjugados. Os balões poderiam remeter à imagem do povo primeiro, e não à figura tranquila do alienista. Da mesma forma, a imagem poderia representar qualquer situação em que o alienista estivesse se dirigindo à sacada. A tensão dramática está justamente no conjunto.

\section{e) Interdependente}

Combinações interdependentes são incomuns, e seus efeitos "mantêm o leitor plenamente envolvido, porque exigem que ele monte o sentido com base em diferentes partes." (MCCLOUD, 2008, p. 137). Nessa combinação, palavra e imagem dependem uma da outra concomitantemente, e, ao contrário da combinação anterior, o terreno comum que elas abrangem não está marcado obrigatoriamente no texto, mas sim no contexto, extrapolando os limites do quadro para depreender algum sentido, podendo ou não haver alguma anacronia entre palavra e imagem. A semelhança do exemplo a seguir com o anterior é só aparente. Uma análise pode revelar as diferenças necessárias para a categorização.

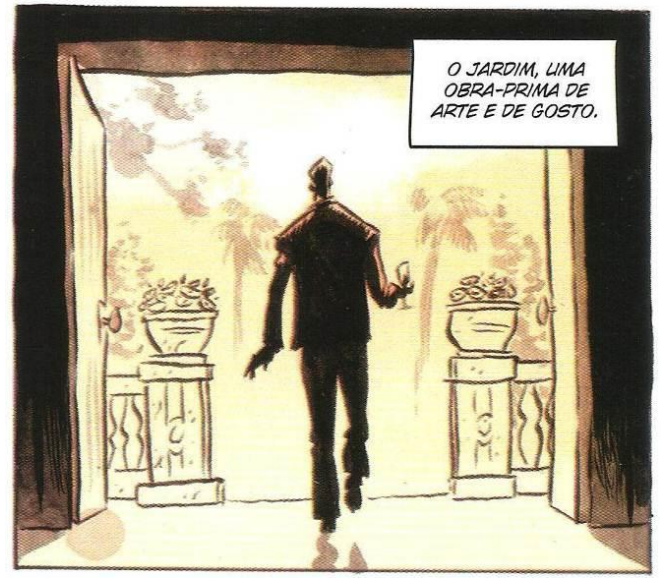

Figura 9: O Alienista. Interdependente. (p. 27). 


\section{Revista do SELL}

v. $4, n^{\circ} .1$

ISSN: $1983-3873$

No fragmento escolhido, o texto verbal não marca o tempo, comunica, de forma atemporal, a exuberância do jardim. O texto visual não mostra o jardim, mostra o personagem Mateus, o albardeiro, caminhando em direção ao jardim, que só é mostrado no quadrinho subsequente. Sem o estrato visual, as palavras poderiam ser tomadas literalmente. Já na imagem, sem o estrato verbal, não seria possível saber da informação sobre o jardim. É por essa relação de complementaridade que palavras e imagem se revezam na formulação de um sentido.

\section{f) Paralela}

Quando palavras e imagens comunicam, cada uma, mensagens aparentemente diversas, sem interseção entre elas, temos uma combinação paralela. Qualquer combinação paralela caracteriza um revezamento, pois palavras e imagens se complementam, embora não tenham nada em comum a princípio, podendo vir a se convergir depois em outra sequência da narrativa.

Desse modo, combinações paralelas sempre mostram uma distinção espacial, e, às vezes, temporal, ou seja, servem para narrar ao mesmo tempo eventos distantes no espaço e/ou no tempo (que ocorrem ou não no mesmo tempo), sendo que cada estrato narra uma combinação desses eventos.
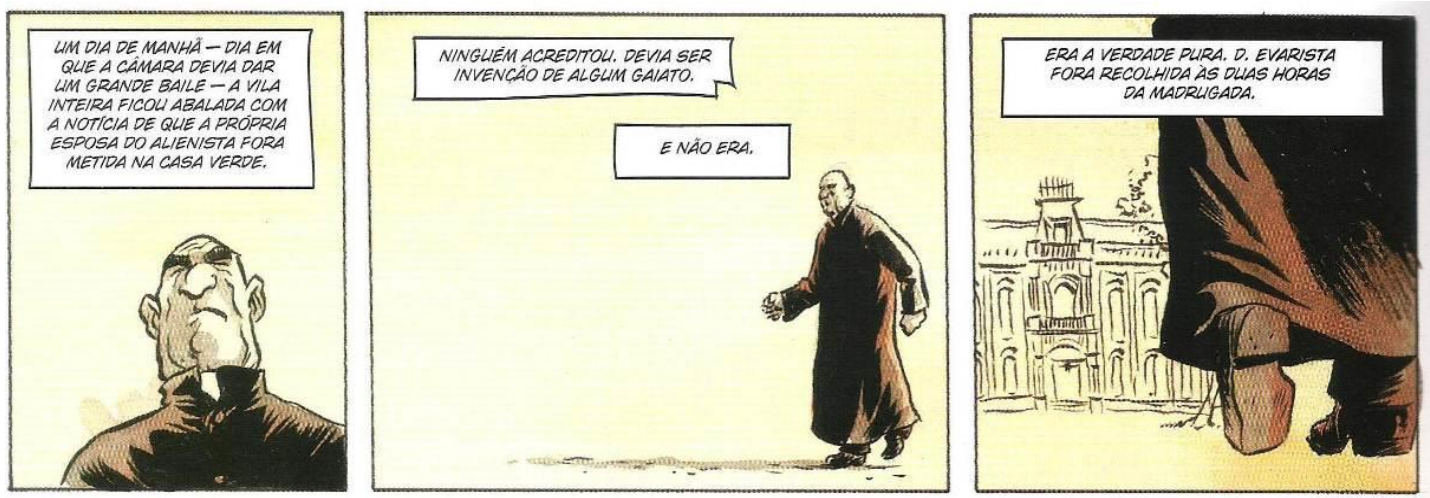

Figura 10: $O$ Alienista. Paralela. (p. 56).

O estrato verbal da sequência acima comunica o recolhimento de $D$. Evarista na Casa Verde, pela madrugada. Já o estrato visual comunica que o Padre Lopes está se dirigindo à Casa Verde, como mostra o Q3. A cena mostrada ocorreu após a prisão de D. Evarista. A ocasião é aquela que o Padre Lopes foi averiguar o fato do recolhimento da esposa do 


\section{Revista do SELL \\ v. $4, n^{\circ} .1$ \\ ISSN: $1983-3873$}

alienista. A convergência temática dos dois estratos só se dá na sequência seguinte, quando Dr. Simão Bacamarte e Padre Lopes estão conversando sobre o ocorrido.

\section{g) Montagem}

$\mathrm{Na}$ combinação por montagem, as palavras são representadas pictoricamente. $\mathrm{Ou}$ elas fazem parte do universo ficcional, ou sua materialidade exerce alguma função no mundo diegético. Desse modo, a relação entre o estrato verbal e o visual é de complementaridade, a representação pictórica da mensagem verbal faz dela, muitas vezes, um signo icônico também.

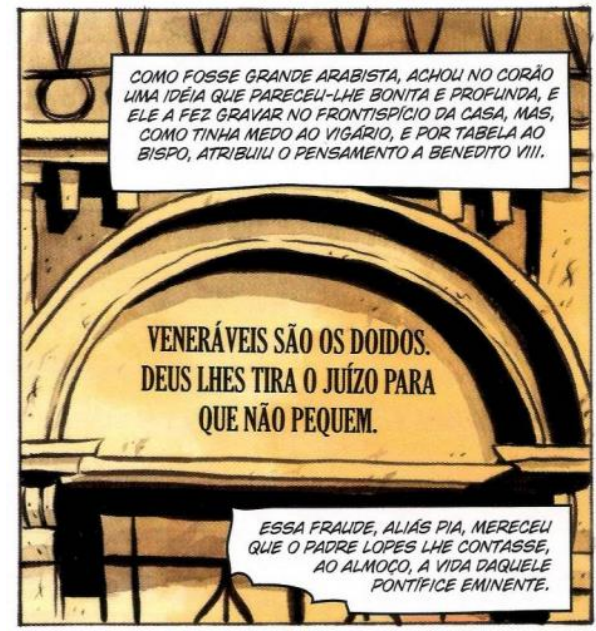

Figura 11: O Alienista. Montagem. (p. 11).

Além da montagem acima, que representa o frontispício da Casa Verde, outras duas podem ser encontradas n'O Alienista: a placa da barbearia de Porfírio, escrita "Canjica", e os manuscritos de Simão, com vários dizeres, muitas vezes ilegíveis.

\subsection{Signos não-verbais: os "silêncios"}

Podemos observar que o silêncio n'O Alienista (e talvez nos quadrinhos de modo geral) é bem estruturado. O silêncio nos quadrinhos é outro signo complexo, um signo nãoverbal, não-fônico, cujo emprego pode assumir inúmeros sentidos. Ele aparece como componente intencional do texto. Podemos encontrá-lo de inúmeras formas, nas sarjetas (ou calhas) e/ou nos enquadramentos. Há ainda casos raros de balões de fala vazios ou com reticências, esses dois casos ausentes n'O Alienista. 


\section{Revista do SELL}

v. $4, n^{\circ} .1$

ISSN: $1983-3873$

\section{a) Calhas}

As calhas, sarjetas ou hiatos nas histórias em quadrinhos são os espaços entre os quadros. A passagem de um quadro a outro no processo narrativo das histórias em quadrinhos depende desses intervalos, e se dá num processo de leitura chamado por McCloud (1995) de conclusão. O significado temporal da progressão narrativa é definido mais pelo conteúdo do quadro e pela relação de um com o outro do que pela sua forma em si. A forma do quadro em si não diz tudo. A exceção seria a ocorrência da analepse ou flashback.

Os conteúdos dos quadros e as relações dialógicas com outros são importantes para designar que ocorre uma manifestação temporal na narrativa. "Nada é visto entre os dois quadros, mas a experiência indica que deve ter alguma coisa lá" (McCLOUD, 1995, p. 67):

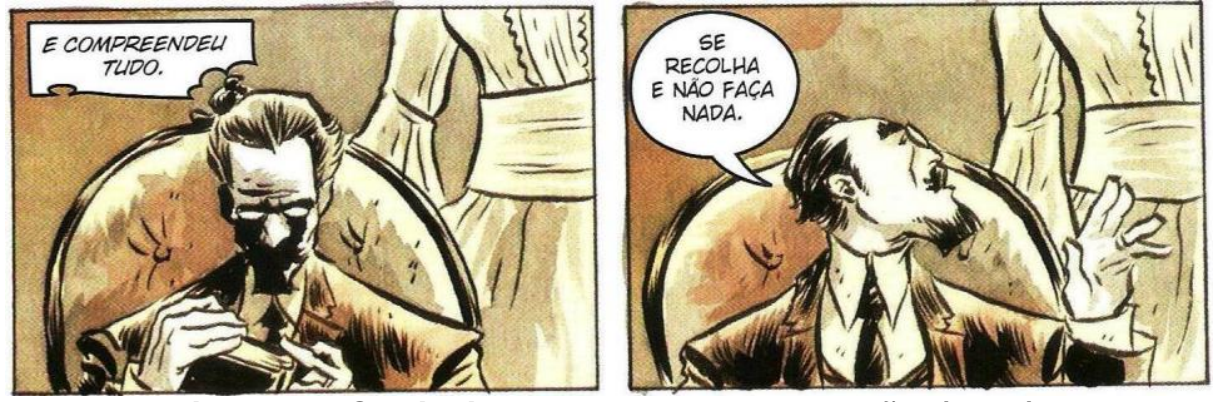

Figura 12: O Alienista. Processo de conclusão. (p. 41).

McCloud (1995) elenca seis categorias de transição de quadro-a-quadro, o que evidencia a complexidade do processo de conclusão e sua importância para os efeitos de sentido da história. São eles: (1) momento-a-momento, (2) ação-a-ação, (3) cena-a-cena, (4) tema-a-tema, (5) aspecto-a-aspecto, (6) non sequitur.

\section{b) Quadros mudo e silencioso}

Por ser uma narrativa visual, os quadrinhos gozam de um recurso ínsito: o uso do silêncio de forma explícita e não anunciada, criando efeitos diversos no processo de leitura, sobretudo com a memória e o tempo, ou com o que é dito e não dito. McCloud (1995) não chega a categorizar os tipos de silêncio(s) presentes nos quadrinhos. Nossa intenção também não é fazer essa taxonomia, mas precisamos diferenciar algumas manifestações para análises posteriores, uma vez que o teórico supracitado utiliza indiferentemente as conjunções quadro mudo, quadro sem som, quadro silencioso, etc. Com base nas informações de McCloud (1995) sobre o silêncio nos quadrinhos e nas observações de 


\section{Revista do SELL \\ v. $4, n^{\circ} .1$ \\ ISSN: $1983-3873$}

ocorrências generalizadas n'O Alienista, elaboramos três maneiras de distinguir esses quadros ou enquadramentos. Como nos quadrinhos, som, tempo e palavra estão relacionados, chamaremos, ad hoc, essa relação entre o som, o tempo e o estrato verbal dos enquadramentos de sonocronografia dos enquadramentos no discurso quadrinístico, que pode ser assim dividida:

(1) Enquadramento sonoro: tem a presença de balões de fala e/ou de onomatopeias. Pode ter ou não a presença de recordatários (com indicações cênicas, falas do narrador ou de personagens). Este tipo de enquadramento sempre diz, faz dizer, e o narrador pode ainda fazer falar no universo diegético através dos balões e outros meios de transmitir o som. É o tipo de enquadramento mais comum. Nele, a relação do tempo com a ação é de igualdade: tempo do som é igual ao tempo da ação.

(2) Enquadramento mudo: tem ausência de balões e onomatopeias. Sempre tem um recordatário ou o seu equivalente. Este tipo de enquadramento diz, faz dizer, mas não faz falar. O narrador tece comentários sobre a ação representada ou não. Pode haver anacronias ou disritmias tempo-espaciais, como nas combinações paralelas entre palavras e imagens (McCLOUD, 1995). É um tipo de quadro muito presente em adaptações literárias que tendem a preservar o texto fonte. A relação do tempo com a ação neste tipo de quadro é de alteridade: o tempo do comentário é diferente do tempo da ação.

(3) Enquadramento silencioso: há ausência total de balões, onomatopeias, ou recordatários. É um tipo de enquadramento que não diz, mas faz dizer. Esse enquadramento, geralmente, é atemporal. O tipo de silêncio evocado aqui necessariamente exclui algum dito para que o dizer seja (novamente) possível.

No fragmento a seguir, temos quadros silenciosos (Q2-4) e quadros mudos (Q1 e Q5): 


\section{Revista do SELL}

v. $4, n^{\circ} .1$

ISSN: $1983-3873$

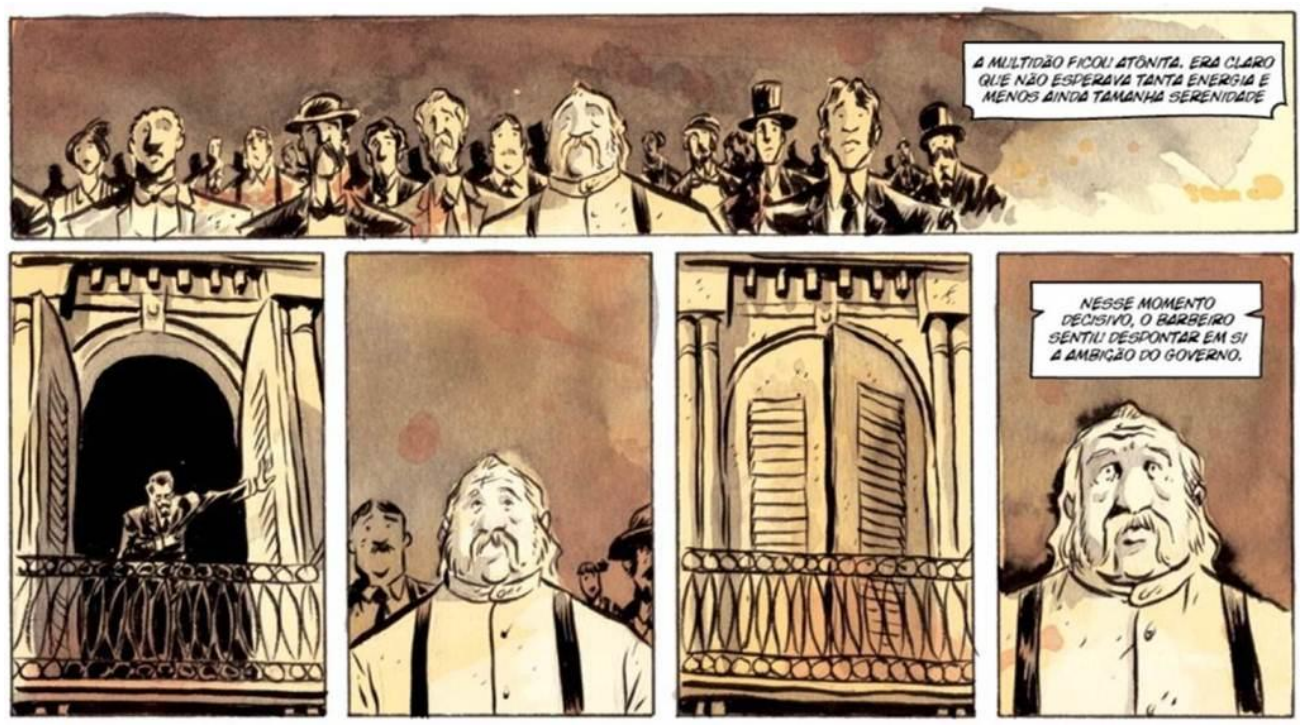

Figura 13: O Alienista. Signos do silêncio. (p. 42-43).

No texto machadiano, grifamos as partes supostamente referentes aos quadros silenciosos, e que foram omitidas no processo de tradução, possibilitando novos sentidos:

Mas o assombro cresceu de ponto quando o alienista, cortejando a multidão com muita gravidade, deu-Ihe as costas e retirou-se lentamente para dentro. $\mathrm{O}$ barbeiro tornou logo a si, e, agitando o chapéu, convidou os amigos à demolição da Casa Verde; poucas vozes e frouxas the responderam. (ASSIS, 1977, p. 34, grifos nossos).

Na proposta acima de diferenciação dos quadros, estabelecemos uma distinção entre dizer e falar, considerando que toda forma de falar está contida nas formas de dizer. De acordo com Ximenes (2000), o verbete dizer guarda como suas significações o ato de "1. Exprimir por palavras. 2. Exprimir por gestos, por escrito, etc.” (XIMENES, 2000, p. 268). Já o verbete falar parece se restringir às manifestações da palavra: "1. Exprimir com palavras. [...]. 3. Dirigir a palavra. 4. Saber conversar (em algum idioma) [...]. 7. Expressar-se por palavras." (XIMENES, 2000, p. 339-340). Disso, apoiamos a ideia de que o silêncio, embora não diga ou fale, ele faz dizer, pois o silêncio é "uma possibilidade do discurso" (MELLO, 2002b, p. 101). O silêncio “"produz um recorte entre o que se diz e o que não se diz'. Ele produz algo como o antiimplícito, produz 'um não-dito necessariamente excluído'. Este silêncio [constitutivo] estabelece o que fica de fora para se poder significar." (MELLO, 2002b, p. 100). ${ }^{6}$

\footnotetext{
${ }^{6}$ Deve-se ter cautela ao trabalhar as formas de silêncio nos inúmeros tipos de discurso, como o literário e o quadrinístico, por exemplo, pelo modo como cada um relaciona suas matérias linguageiras. Por ser ainda uma temática recente nos estudos da linguagem, atribui-se ao silêncio diversas conotações, como silêncio falante, silêncio eloquente, etc. Os trabalhos sobre o silêncio situam-se em diferentes domínios científicos, filosóficos e psicanalíticos, de modo que as
} 


\section{Revista do SELL \\ v. $4, n^{\circ} .1$ \\ ISSN: $1983-3873$}

A comparação que McCloud (1995) fez dos quadrinhos ocidentais com os orientais mostrou que nestes últimos o conteúdo implícito, silenciado, omitido é muito mais valorizado como fonte de significado do que nos primeiros. "A ideia de que os elementos omitidos de uma obra são tão partes dela quanto os incluídos é típica do oriente há vários séculos." (McCLOUD, 1995, p. 82).

N'O Alienista, o silêncio muitas vezes substitui passagens do texto machadiano. Se no texto fonte a palavra direciona a interpretação do leitor por eventuais ambiguidades ou alusões, no quadrinho a ausência de palavras expande a possibilidade de sentidos (não há ancoragem ou revezamento na superfície textual, mas, por ser uma tradução intersemiótica, pode haver uma relação com a palavra machadiana omitida). O silêncio traz a possibilidade de outras vozes, sem calar a voz machadiana (calar e silenciar são operações distintas aqui).

\section{Considerações finais}

Os quadrinhos têm um sistema semiótico particular, diferente de outros sistemas que também conjugam "palavras e imagens". Neste trabalho, abordamos alguns aspectos da gramática dos quadrinhos. Ao mostrarmos como os elementos constituintes da linguagem quadrinística presente n'O Alienista se organizam, se concatenam, demos foco à sua sintaxe. A sua semântica é um aspecto que deve ser abordado levando-se em conta outros pontos de formação de sentido, posto que esse aspecto excede uma abordagem estrutural, estando atrelado ao contexto e ao cotexto.

Nossa intenção não foi mostrar um fazer técnico, embora parecesse. Devemos ressaltar que há uma diferença em mostrar o fazer técnico e os aspectos estruturais dessa semiótica particular que consideramos como a linguagem dos quadrinhos. $\mathrm{O}$ primeiro consistiria em mostrar como fazer, o segundo consiste em mostrar como pode ser feito.

Defendemos que o sentido se apoia em três pontos que devem ser analisados: o sistema, os sujeitos, a situação histórica. Tentamos mostrar um pouco do sistema. Podese estudar a interação dos sujeitos e o contexto sócio-histórico da obra, mas sem compreender como funciona o sistema da linguagem, sem o entendimento desses aspectos da gramática dos quadrinhos, podemos afirmar que o entendimento dos efeitos de sentido do discurso quadrinístico fica comprometido. 


\section{Revista do SELL}

v. $4, n^{\circ} .1$

ISSN: $1983-3873$

\section{Referências:}

ASSIS, M. O alienista. 5aㅡ ed. São Paulo: Ática, 1977.

BARTHES, R. Rhétorique de l'image. Communications, n. 2, vol. 4, p. 40-51. Paris, 1964.

BARTHES, R. A retórica da imagem. In: O óbvio e o obtuso: ensaios críticos III. Trad. Léa Novaes. Rio de Janeiro : Nova Fronteira, 1990, p. 27-43.

BOWCHER, W. L. Field and multimodal texts. In: HASAN, R.; MATHIESSEN, C.; WEBSTER, J. Continuing discourse on language: a functional perspective. Vol. 2. Equinox, 2007, p. 619-646.

CHARAUDEAU, P. Visadas discursivas, gêneros situacionais e construção textual. In: MACHADO, I. L.; MELLO, R. (Orgs). Gêneros: reflexões em análise do discurso. Belo Horizonte: NAD/FALE/UFMG, 2004, p. 13-41.

COSTA, L. P. A. O alienista, de Fábio Moon e Gabriel Bá: uma análise do discurso quadrinístico. 2013, 213 f. Dissertação (Mestrado em Letras) - Universidade Federal de Viçosa, Minas Gerais.

EISNER, W. Narrativas gráficas. Trad. Leandro Luigi Del Manto. São Paulo: Devir, 2005.

JOLY, M. L'image et les signes: approche sémiologique de l'image fixe. Paris: Nathan, 1994.

JOLY, M. Introdução à análise da imagem. São Paulo: Papirus Editora, 2007.

McCLOUD, S. Desvendando os quadrinhos. São Paulo: Makron Books, 1995.

McCLOUD, S. Desenhando quadrinhos. São Paulo: Makron Books, 2008.

MELLO, R. Análise discursiva do(s) silêncio(s) no texto literário. In: MACHADO, I. L.; et alii. Ensaios em análise do discurso. Belo Horizonte: FALE/UFMG, 2002b, p. 87-123.

MELO, M. S. S. Estratégias discursivas em publicidade de televisão. 2003. 302 f. Tese (Doutorado em Linguística). Universidade Federal de Minas Gerais, Belo Horizonte, Minas Gerais.

MOON, F. Gula e a arte final. 10 Pãezinhos. 2011. Disponível em: http://10paezinhos.blog.uol.com.br/arch2011-03-01_2011-03-31.html. Acesso em: 20 out. 2012.

MOON, F.; BÁ, G. O Alienista: Machado de Assis: adaptação em quadrinhos. Rio de Janeiro: Agir: 2007.

PEYTARD, J. La place et le statut du 'lecteur' dans l'ensemble 'public'. Semen, n. 1, 1983. Versão on line de 2007. Disponível em: http://semen.revues.org/4231. Acesso em: 04 de janeiro de 2012. 


\section{Revista do SELL}

v. $4, n^{\circ} .1$

ISSN: 1983-3873

RAMOS, P. A leitura dos quadrinhos. São Paulo: Editora Contexto, 2010.

XIMENES, S. Minidicionário Ediouro da língua portuguesa. 2a․ ed. São Paulo: Ediouro, 2000. 